\title{
OS SENTIDOS DE BULL YING NAS VOZES DAS CRIANÇAS DO ENSINO FUNDAMENTAL: APRENDENDO E CRESCENDO COM OS CONFLITOS NA ESCOLA
}

\section{THE SENSES OF BULLYING IN THE VOICES OF FUNDAMENTAL TEACHING CHILDREN: LEARNING AND GROWING UP WITH SCHOOL CONFLICTS}

\author{
FREITAS, Maíra de Oliveira ${ }^{1}$ \\ BORGES, Luís Paulo Cruz ${ }^{2}$ \\ CARVALHO, Julia Tavares de ${ }^{3}$
}

\begin{abstract}
RESUMO
O presente trabalho tem como objetivo apresentar análises e reflexões sobre os sentidos do bullying a partir das vozes das crianças. As atividades foram desenvolvidas no projeto de Iniciação à Docência, que ocorre em turmas dos Anos Iniciais do Ensino Fundamental do CApUERJ e tem como título "Aprendendo e crescendo com os conflitos na escola: o respeito ao outro a serviço do desenvolvimento no ensino". Nas rodas de discussão em sala de aula, focalizamos temas como tolerância, respeito e justiça. Para a elaboração e desenvolvimento do projeto, apoiamo-nos nos estudos de autores que discutem autonomia moral. Como pressupostos metodológicos, operamos a partir da pesquisa-ação em que produzimos informações e conhecimentos sobre a ação pedagógica cotidiana. Além da observação, também trabalhamos com o diário de campo como forma de registro das atividades, escrita e imagens. Como análises e reflexões iniciais, temos: i) O diálogo deve ser entendido como uma prática pedagógica; ii) A construção de um debate que envolva autonomia moral e ética requer o entendimento de que a criança é sujeito ativo no processo de dialogicidade e reflexão sobre o mundo.
\end{abstract}

PaLAVRaS-chave: Bullying; Violência; Autonomia moral; Sala de aula; Iniciação à docência

\begin{abstract}
The present work aims at presenting analyzes and reflections on the meanings of bullying through the voices of children. The activities were developed in the Initiation to Teaching project, which takes place in classes from the Early Years of Primary Education at CAp-UERJ and is entitled "Learning and Growing with Conflicts in School: Respect for Others in the Service of Development in Teaching". In plenaries for discussion in the classroom, we focus on topics

\footnotetext{
${ }^{1}$ Universidade do Estado do Rio de Janeiro (UERJ). Professora do Instituto de Aplicação Fernando Rodrigues da Silveira da Universidade do Estado do Rio de Janeiro (CAp-UERJ). Rio de Janeiro, RJ, Brasil. e-mail: freitasmaira@yahoo.com.br

2 Universidade do Estado do Rio de Janeiro (UERJ). Professor do Instituto de Aplicação Fernando Rodrigues da Silveira da Universidade do Estado do Rio de Janeiro (CAp-UERJ). Rio de Janeiro, RJ, Brasil. ORCID: https://orcid.org/0000-0002-2153-5229 e-mail: borgesluispaulo@yahoo.com.br

3 Universidade do Estado do Rio de Janeiro (UERJ). Professora do Instituto de Aplicação Fernando Rodrigues da Silveira da Universidade do Estado do Rio de Janeiro (CAp-UERJ). Rio de Janeiro, RJ, Brasil. e-mail: juliadecarvalho@gmail.com
} 
DOI: $10.12957 / \mathrm{e}-\mathrm{mosaicos} .2019 .42284$

such as tolerance, respect and justice. For the elaboration and development of the project, we rely on the studies of authors who discuss moral autonomy. As methodological assumptions, we operate from action research in which we produce information and knowledge about everyday pedagogical action. In addition to the observation, we also work with the field diary as a means of recording activities, writing and images. As for initial analyzes and reflections, we have: i) Dialogue should be understood as a pedagogical practice; ii) The construction of a debate that involves moral and ethical autonomy requires the understanding that the child is an active subject in the process of dialogue and reflection on the world.

KeYWORDS: Bullying; Violence; Moral autonomy; Classroom; Tutoring

\section{INTRODUÇÃO}

Os conflitos entre crianças são recorrentes no ambiente escolar, sendo inevitável em qualquer relação social. Não importa a idade dos estudantes, as situações que geram tensões estão presentes em brincadeiras, em debates, em atividades na sala de aula ou na quadra esportiva. Em alguns casos, a resolução pode não oferecer grandes desafios para os envolvidos, mas às vezes demandam auxílio de outros atores, como docentes, para problematizar e potencializar a questão.

Há quem diga que temos hoje uma carência de sabedoria individual e coletiva para lidar com situações de conflito. Questões como indisciplina, falta de limites e desrespeito são alguns dos obstáculos enfrentados por professores e alunos para o sucesso do trabalho escolar - seja em termos da dimensão epistêmica do ensino, dimensão socializante da escola ou da dimensão profissionalizante da educação. Além disso, observamos também comportamentos e falas marcadas pela intolerância e desrespeito. Quando esses conflitos não são resolvidos, podem ocasionar até mesmo a violência física.

Esse quadro configura um grande desafio para os profissionais da Educação atualmente. A sociedade espera mais participação política das pessoas, mais diálogo, mais tolerância e respeito, para além de pessoas bem formadas para assumir quaisquer postos de trabalho. Não bastassem essas complexas demandas que a instituição escolar tem o compromisso de lidar, a escola vem assumindo sua responsabilidade de pensar nas melhores maneiras e estratégias para lidar com os conflitos que nela se apresentam.

Foi pensando em tudo isso que o projeto "Aprendendo e crescendo com os conflitos na escola: o respeito ao outro a serviço do desenvolvimento no ensino" foi concebido. Concordamos com Devries e Zan (1998), quando pontuam que a escola não é um espaço neutro e, independentemente da preocupação, os professores e agentes estão engajados na educação social e moral das crianças, configurando-se, portanto, uma espécie de currículo implícito, ou seja, as normas e valores, principalmente os relacionados à disciplina, que estão embutidos na estrutura social das escolas (DEVRIES; ZAN, 1998).

Observamos, com frequência, que as crianças têm procurado resolver seus conflitos por meio de agressão física e verbal, seja em sala de aula, ou durante outras 
DOI: $10.12957 / \mathrm{e}-\mathrm{mosaicos} .2019 .42284$

atividades na escola. A necessidade da intervenção docente com foco na mediação desses conflitos é recorrente. De acordo com De La Taille (2000), quando criamos uma regra de controle em vez de discutir os valores envolvidos nessa situação, criamos uma sociedade infantil. No momento em que as pessoas precisam de regras e leis externas para regular seu próprio comportamento, estamos diante de um problema moral (DE LA TAILLE, 2000). Em consonância com as colocações do autor, reconhecemos e defendemos a necessidade de a escola dedicar um espaço-tempo para debates, discussão dos conflitos e de regras que garantam a convivência social. Concordamos, portanto, que se aprende a mediar os conflitos, ou seja, não é uma aprendizagem espontânea. Compreendemos também que a escola deve ser um ambiente afetivo, uma vez que a afetividade não está dissociada do desenvolvimento intelectual. Portanto, entendemos o conflito como uma possibilidade de desenvolvimento e não, necessariamente, como um problema.

As questões de estudo que nos guiam indicam lacunas importantes no debate sobre a mediação de conflitos no ambiente escolar. É notório que as formas de mediação de conflitos em nossa sociedade, se mostram, a cada dia, mais intolerantes, agressivas e, consequentemente, ineficazes. Assim, o projeto se apresenta como importante possibilidade de diálogo e debate dentro do CAp-UERJ sobre temas muito caros ao ambiente escolar como tolerância, respeito, justiça, liberdade, cooperação, cidadania dentre outros. Compreendemos, também, que é de muita relevância a orientação aos bolsistas em um ambiente crítico, onde a prática docente seja (re)avaliada e (re)construída diariamente. Portanto, buscamos estimular um trabalho de reflexão crítica sobre a prática e de reconstrução permanente da identidade pessoal e profissional se apropriando do projeto pedagógico da escola.

Diante do exposto, o presente trabalho tem por objetivo apresentar análises e reflexões sobre os sentidos do bullying partir das vozes das crianças dos Anos Iniciais do Ensino Fundamental. As atividades foram desenvolvidas no bojo das ações de um projeto de iniciação à docência encetado no CAp-UERJ em 2016, intitulado "Aprendendo e crescendo com os conflitos na escola: o respeito ao outro a serviço do desenvolvimento no ensino", o mesmo é desenvolvido em duas turmas dos Anos Inicias do Ensino Fundamental no Instituto de Aplicação Fernando Rodrigues da Silveira/ CAp-UERJ. O projeto conta com a participação de Professores Assistentes da UERJ, que atuam como professores regentes das turmas e uma bolsista de Iniciação à docência, graduanda do curso de Pedagogia da Faculdade de Educação da UERJ.

As crianças-estudantes e fazedoras, também, desse projeto constituíam três turmas do $3^{\circ}$ ano do Ensino Fundamental, entre 2016 e 2018, e tinham idades entre 8 e 9 anos. Moradoras de diversos bairros da cidade do Rio de Janeiro e com origens sociais distintas, crianças cujos pais tinham escolaridade variável (desde o Ensino Fundamental incompleto ao Ensino Superior). No universo de 60 crianças, existia um número de ingressantes por cotas, sistema presente no CAp-UERJ desde $2014^{4}$.

\footnotetext{
4 "Assembleia Legislativa do Rio (ALERJ) aprovou nesta terça-feira (9) o projeto de lei que cria cotas para as admissões no Instituto de Aplicação Fernando Rodrigues da Silva (CAp-Uerj). O projeto é do governo do estado e faz previsões de cotas para estudantes negros, pardos e índios (20\%), estudantes oriundos da rede pública
} 
DOI: $10.12957 / \mathrm{e}-m o s a i c o s .2019 .42284$

Quanto ao gênero destaca-se o quantitativo de meninas presentes nas turmas, sendo este um grupo maior que os meninos.

Nosso objetivo com o trabalho realizado diariamente é promover discussões que possam contribuir para a formação moral dos estudantes, de modo que possam ser capazes de resolver conflitos coletivamente não apenas no espaço escolar, como em quaisquer espaços que circulem. Compreendemos a complexidade e, por que não, a subjetividade que esse objetivo traz. Por isso, buscamos esclarecer e, acima de tudo, dialogar com as crianças, sobre a importância da escuta e do respeito para com as pessoas. Independentemente de serem nossos pares, nossos familiares, nossos professores ou quaisquer pessoas com quem, de alguma forma, estabelecemos alguma relação, não há espaço para desrespeito e intolerância.

Dito isso, elencamos a seguir os objetivos específicos que nortearam o planejamento de nossas atividades e orientaram as discussões promovidas em sala de aula com os estudantes: (1) Envolver os alunos no processo de mediação de conflitos; (2) Estimular os alunos a assumirem responsabilidades dentro e fora do ambiente escolar; (3) Estimular os alunos a participarem ativamente da construção das regras da sala, assumindo-as com o coletivo da escola; (4) Estabelecer e ampliar as relações sociais articulando os interesses dos alunos e pontos de vista com os demais, desenvolvendo atitudes de ajuda e colaboração; (5) Investigar quais são as causas dos conflitos em sala de aula com vistas à reflexão acerca da questão; (6) Promover ações que estimulem a autonomia moral; (7) Promover discussões e espaços de participação; (8) Estimular a participação das famílias no processo de autonomia moral dos alunos.

Como pressupostos metodológicos, operamos a partir da pesquisa-ação em que produzimos informações e conhecimentos sobre a ação pedagógica cotidiana. As observações de sala de aula ocorreram semanalmente, e quinzenalmente aconteciam as reuniões de planejamento e debate sobre as propostas do projeto. Dessa forma, trabalhamos a partir da ideia de ação-reflexão-ação para, assim, produzirmos conhecimentos na e sobre a prática. Além da observação, também, operamos com o diário de campo como forma de registro das atividades, produzindo escrita de relatórios e um banco de imagens.

A pesquisa-ação é uma metodologia que se baseia na autorreflexão, sobretudo, a coletiva. Autorreflexão que está baseada numa ideia de justiça social importante para um trabalho ético no campo educacional.

Pesquisa-ação é uma forma de investigação baseada em uma autorreflexão coletiva empreendida pelos participantes de um grupo social de maneira a melhorar a racionalidade e a justiça de suas próprias práticas sociais e educacionais, como também o seu

(20\%) e pessoas com deficiência (5\%)." O GLOBO, 09 de Abril de 2013. Acesso em 21 de Agosto de 2019: Disponível em: https://oglobo.globo.com/sociedade/educacao/alerj-aprova-projeto-de-lei-que-preve-cotaspara-cap-uerj-8071217 
entendimento dessas práticas e de situações onde essas práticas acontecem... (KEMMIS; MC TAGGART, 1988, p. 83).

Queremos evidenciar neste artigo, que a pesquisa-ação nos auxiliou em um processo de reflexividade constante e que as temáticas abordadas em todo o projeto são fruto desse movimento de autorreflexão para pensarmos e produzirmos conhecimento em educação.

Neste estudo, os estudantes são entendidos como agentes do conhecimento, potencialmente transformadores da escola. Suas vozes são potências para um maior entendimento e compreensão sobre a realidade das escolas (MATTOS E CASTRO, 2010).

\section{AS RODAS COMO PRÁTICAS DE DIÁLOGO EM SALA DE AULA}

Ficar zoando as pessoas, ficar chamando de tampinha e várias outras coisas. O Cebolinha chama a Mônica de dentuça, gordinha e baleia. Nunca pratique bullying, é muito chato! (Laís, T. 32, $3^{\circ}$ ano do Ensino Fundamental, CAp-UERJ).

É comum nós, enquanto docentes, reproduzirmos, a fala sobre a importância da escola se ocupar do desenvolvimento da postura crítica e de posicionamentos respeitosos dos alunos, mas pouco falamos sobre as formas de promover isso. Estamos convencidos de que não há uma fórmula ou receita para isso, mas há uma série de estudos e correntes teóricas que nos oferecem elementos para pensarmos em caminhos possíveis para promovermos espaços e atividades em prol do desenvolvimento moral das crianças.

Os conflitos ocorrem diariamente no espaço escolar. Os desentendimentos ocorridos entre as crianças são pauta das rodas de conversa em sala de aula. As rodas de conversa fazem parte do trabalho do CAp-UERJ, em todos os anos de escolaridade acontecem diariamente conforme nos dizem Braun et al (2009), mais do que uma forma de dinamizar o aprendizado ou efetivar um objetivo curricular, as rodas têm representado uma oportunidade de diálogo, conhecimento, pesquisa e aprendizado, não só para os alunos, como também para nós, professoras e professores.

Nesse espaço, as crianças relatam os problemas ocorridos sobre a própria ótica e ouvem a versão dos colegas. A turma é estimulada a se posicionar, sempre buscando, coletivamente, refletir sobre a melhor alternativa a ser seguida, caso um novo episódio daquela natureza ocorra. Parece não haver muita novidade nesse processo, mas observamos o quanto as crianças crescem nesse espaço de escuta e de fala. A qualidade das argumentações é o nosso foco, e muito mais do que dizer o que é certo e/ou errado, as crianças são estimuladas a se expressarem. As conclusões são debatidas em grupo.

As vozes dos participantes são evocadas, mas não em um sentido de ilustração, ou seja, de mera corroboração para algo já existente. Antes de tudo, parte-se de tais 
DOI: $10.12957 / \mathrm{e}-\mathrm{mosaicos} .2019 .42284$

vozes para se construir uma teorização com e para as infâncias que estão presentes na escola (ALVES; MATTOS, 2015), uma teorização de como os estudantes se relacionam com o conhecimento e a cultura escolar.

Refletir sobre a prática, subverter o senso-comum, a ordem vigente nas escolas e o pensamento conservador, que cresce exponencialmente em nossa sociedade, foram questões que pautaram todo o trabalho. (Re)pensar e (auto)criticar o autoritarismo do professor, o ambiente coercivo e o lugar do "bom aluno submisso e obediente", significa colaborar com uma sociedade democrática e com a ideia básica de liberdade e justiça. Nesse sentido, o papel do professor ou professora é problematizar as questões que surgem, compreendendo-se como participante dessa roda, desafiando e estimulando a participação de todos.

Não bastasse isso, vemos nas atividades intencionais uma oportunidade para direcionarmos as discussões para um foco que não necessariamente é novo para eles, mas que pode ser, então, mais problematizado. Durante o planejamento desses momentos, pensamos na reflexão que vamos provocar, no papel da escuta e no posicionamento das crianças diante de uma determinada questão. Essas situações podem, potencialmente, gerar opiniões divergentes ou mesmo relatos de experiências diversas, fazendo com que os alunos olhem para seu próprio posicionamento com novos olhos. Dessa forma, são, portanto, estimulados a se colocarem no lugar do outro ou se "distanciarem" das próprias vivências para compreender o que o Outro está tentando dizer.

Compreender o Outro é compreender a si mesmo rompendo fronteiras, por vezes tão fixas e sem sentido. As vozes em sala de aula, então, tornam-se narrativas das experiências humanas que, concomitantemente, são permeadas por uma miríade de sentidos de Outros.

Tratando-se de crianças, isso é especialmente complexo, mas pensamos ser fundamental para elaborarem seus posicionamentos, seus argumentos, além de uma postura de escuta e respeito. Enquanto professores e professoras, buscamos orientar as discussões mostrando a importância do bem comum, da tolerância, da justiça, dos direitos de cada um. Conforme nos sugerem Braun et al(2009), sobre a finalidade da roda:

A interlocução entre os alunos, favorecendo estratégias de apropriação e construção do conhecimento, uma vez que tendo sua palavra em circulação, os alunos garantem que ideias, experiências e narrativas, sejam valorizadas, ouvidas e, tematizadas coletivamente (BRAUN et al, 2009, p. 20).

De acordo com Arroyo (2007), temos pouco conhecimento a respeito do impacto da violência sobre os processos de aprendizagem escolar de crianças e adolescentes, sobretudo nas camadas pobres. Um assunto recorrente tanto em sala de aula, seja nas rodas de conversa ou em reuniões de pais, quanto nas mídias é o assunto bullying. Muito se fala sobre o tema, a sociedade tem se mostrado preocupada 
DOI: $10.12957 / \mathrm{e}-\mathrm{mosaicos} .2019 .42284$

com a temática, no entanto o termo bullying passou a ser falado no senso comum de forma genérica. A Associação Brasileira de Proteção à Infância e Adolescência (ABRAPIA) propõe que o termo bullying seja compreendido como ações agressivas, físicas ou verbais, intencionais e repetidas, que ocorrem entre os estudantes sem um motivo específico, em que um indivíduo ou mais causam angústia e dor ao outro, estabelecendo assim uma relação desequilibrada de poder.

O pesquisador Dan Olweus, da Universidade de Bergan na Noruega, desenvolveu os primeiros critérios para pensarmos o fenômeno social como objeto de investigação. Contribuindo, sobremaneira, em novos estudos e pesquisas que dessem conta de categorizar ações específicas.

Dan Olweus, pesquisador da Universidade de Bergan, desenvolveu os primeiros critérios para detectar o problema de forma específica, permitindo diferenciá-lo de outras possíveis interpretações, como incidentes e gozações ou relações de brincadeiras entre iguais, próprias do processo de amadurecimento do indivíduo (FANTE, 2005, p. 45).

No âmbito escolar, o bullying pode ser entendido como um fenômeno social que afeta de forma intensa diversas dimensões dos estudantes. Assim sendo, pode desencadear ações e distúrbios capazes de interferirem no processo de ensinoaprendizagem da vítima.

É um fenômeno devastador, podendo vir a afetar a autoestima e a saúde mental dos adolescentes, assim como desencadear problemas como anorexia, bulimia, depressão, ansiedade e até mesmo o suicídio. Muitas crianças vítimas do bullying desenvolvem medo, pânico, depressão, distúrbios psicossomáticos e geralmente evitam voltar a escola quando esta nada faz em defesa da vítima (GUARESCHI; SILVA, 2008, p. 17).

Lopes Neto (2005) afirma que a dimensão intencional e repetitiva causa dor e angústia dentro de um espectro desigual de poder. Tais relações, assimétricas, indicam que o bullying pode ser compreendido como:

[...] todas as atividades agressivas intencionais e repetitivas, que ocorrem sem motivação evidente, adotadas por um ou mais estudantes contra outro(s), causando dor e angústia, sendo executados dentro de uma relação desigual de poder. Essa assimetria de poder associada ao bullying pode ser consequente da diferença de idade, tamanho, desenvolvimento físico ou emocional, ou do maior apoio dos demais estudantes (LOPES NETO, 2005 p.165).

Sabemos que a violência na escola é um dos sintomas da crise das relações sociais que estamos vivenciando e que, portanto, não se restringe à esfera escolar 
DOI: $10.12957 / \mathrm{e}-\mathrm{mosaicos} .2019 .42284$

somente. No entanto, partimos do pressuposto que a escola é importante no desenvolvimento dos sujeitos e esta, por sua vez, ainda se mostra como um mecanismo de socialização. Diante disso, a temática apresentada emergiu a partir das discussões em sala de aula e, atentos às demandas e as possibilidades que tais discussões gerariam, os professores fomentaram práticas que colocassem em voga um assunto tão relevante como o bullying, entendendo assim o conflito como oportunidade e não se esquivando dos embates que tais propostas poderiam ocasionar.

\section{OS SENTIDOS DE BULLYING NAS VOZES DAS CRIANÇAS}

Ao compreendermos a roda de conversa como prática pedagógica, abrimos espaço para diversas discussões e nos comprometemos com o aprofundamento teórico e prático tanto dos estudantes quanto dos professores e professoras com a temática. Assim, atentos às demandas, os professores trouxeram textos, charges, histórias e reportagens que ampliaram a possibilidade de interação entre os alunos e que problematizassem ainda mais os questionamentos levantados. Temas como racismo, pobreza, democracia, representatividade, feminismo e solidariedade foram alguns dos discutidos ao longo do projeto.

A discussão sobre bullying, que pretendemos relatar nesse trabalho, fez parte desses momentos de conversa. Em roda perguntamos o que as crianças entendiam sobre o assunto, levantando os conhecimentos prévios de cada uma, de forma que elas escrevessem em uma ficha suas respostas. Depois cada criança foi lendo seu conceito/ sua ideia sobre o tema no coletivo.

PARA VOCÊ, O QUE É BULLYING?

1 - Chamar pessoas de baleia e de tampinha. (Nicolas)

2 - Chamar de Bolofofo e burro. (Victor)

3 - Quando chama de gorda e baleia. (Nicolle)

4 - Reclamar e brigar com as pessoas que não fizeram nada. (Camily)

5 - Zoar as pessoas pelo sexo. (Miguel)

6 - É xingar. (Alexandre)

7 - É uma coisa feia, tipo chamar de baleia. (Guilherme)

8 - Zoar uma pessoa. (Gustavo)

9 - É xingamento, malcriação, falta de educação e falta de respeito. (Maria Fernanda)

10 - Chamar o outro de saco de areia, baleia e tampinha. (Caio)

11 - É maltratar alguém, porque isso pode te levar a briga. (Bruna)

12 - Chamar de tampinha, dentuça e baleia. (Catharina) 
DOI: $10.12957 /$ e-mosaicos.2019.42284

13 - Chamar uma pessoa de uma coisa que ela se ofende e quando é com a mesma pessoa. Também quando a pessoa não é respeitada. (Mariana)

14 - Xingamentos que ofendem as pessoas. (Pedro) 15 - Xingamento que se repete sempre com as mesmas pessoas, que podem ser faladas ou feitas pelo corpo. (Manuela) 16 - É desrespeitar e ofender outra pessoa. (Ana Júlia) 17 - É uma brincadeira de mau gosto. (Phillip)

(Roda de I.D. do dia 13/06/2018 - Turma 32)

Após a leitura de cada criança, ainda em roda, fomos problematizando os conceitos a partir das experiências vividas na escola, em sala ou no recreio. Assim, cada estudante relatou momentos que sofreram interferências de outras crianças. Depois, lemos o texto "Bullying: brincadeiras que ferem". E voltamos ao processo de problematização que não terminou numa única roda, mas que ocorreu em um mês de forma semanal.

Toda semana lemos um texto jornalístico sobre bullying debatendo impressões e experiências. Também, ao final de cada texto propúnhamos uma reflexão, em forma de questionamento moral, sobre o bullying. Reflexões que surgiram a partir dos próprios relatos das crianças na roda.

Reflexão: Na escola de Antônia, um grupo de colegas sempre deixa uma menina de lado porque ela é tímida, nunca deixando-a brincar. Como a turma poderia resolver a situação?

Reflexão: Heitor sofre perseguições de um grupo de colegas com zoações e intimidações. Ele anda muito triste e com medo de ir para a escola. Como vocês poderiam ajudar o Heitor?

Reflexão: Luísa está sofrendo agressões pela internet, como insultos, zoações e boatos maldosos sobre ela. Qual atitude ela deveria tomar? Como vocês a ajudariam?

Ao longo das atividades foram trabalhados diversos temas que partem de conflitos do cotidiano da sala de aula, tais como: regras de convivência, representatividade na turma, representatividade dos negros, democracia, gênero e sexualidade, dentre outros. Buscamos, através de perguntas e questionamentos, a partir dos elementos trazidos, instigar os alunos, com textos, questionamentos que os fizessem desestabilizar em suas hipóteses pré-concebidas. Assim trazendo temas que na contramão a esses ideais, estimulamos que refletissem para que pudessem dialogar e criar novas possibilidades de óticas do mundo.

No decorrer dos diálogos pudemos observar resultados significativos no que diz respeito ao comportamento e nas relações entre os estudantes. Durante as 
DOI: $10.12957 / \mathrm{e}-\mathrm{mosaicos} .2019 .42284$

experiências de formação, entre observar e lecionar nas atividades, pode-se presenciar diálogos bem interessantes das crianças. As frases, ditas com espontaneidade, criaram uma possibilidade analítica e reflexiva sobre o processo de formação inicial docente. Também trouxeram questões sobre: i) a naturalização de ideias preconceituosas concebidas desde a infância, ii) a reprodução de ideias sem questionamento, e a iii) formação do estudante para vida adulta.

Primeiramente, destaca-se a naturalização de ideias preconceituosas concebidas desde a infância. Pôde-se observar ao longo do tempo uma crescente onda de conservadorismo no Brasil em todas as instâncias da sociedade. Encontra-se desde propostas nas políticas públicas que atacam diversos programas sociais e criam leis com o objetivo de deteriorar diferentes partes da área pública até em propostas de atividades pedagógicas sem embasamento teórico e reproduzindo múltiplos preconceitos.

Operamos contra uma reprodução de ideias sem questionamento presentes nas vozes das crianças. Durante os planejamentos, as rodas, as discussões e debates sempre aventamos como possibilidade uma reflexividade crítica. Por isso mesmo, 0 questionamento é forma/conteúdo do nosso trabalho em sala de aula. O ensino é um processo que deve ser compreendido como mediação, muito mais do que uma mera transmissão de conteúdos.

Por fim, compreendemos o forte papel da escola na formação do estudante para vida adulta. Esse tópico evidencia um desafio à escola moderna que (re)pensa seus estudantes como atores sociais numa perspectiva de autonomia e criticidade diante da realidade social no hoje. Também traz novas demandas para pensarmos os papeis coletivos e político na escola pública diante da alteridade presente em seus espaçostempos.

Ao perceber sinais de bullying na escola, é fundamental entender como isso acontece. Como explicitado ao longo deste artigo, o projeto de Iniciação à Docência desenvolvido no CAp-UERJ promove espaços em sala de aula para as rodas de conversa para que situações de conflito sejam debatidas. Este momento permite que as crianças se coloquem no papel tanto do agressor quanto da vítima e do espectador e podem mostrar como se sentem. Além disso, entendendo que este é um espaço de produção de conhecimento e reflexão sobre as práticas, é um campo necessário e importante para estudantes de Educação. A participação em projetos dessa natureza oferece uma oportunidade única de observar e fazer parte de um processo de construção de conhecimento ensejados por estudantes e docentes. Deste modo, estimulamos a reflexão sobre a prática docente in loco.

\section{CONSIDERAÇÕES FINAIS}

O presente artigo socializou dados de um projeto de Iniciação à Docência realizado dentro do CAp-UERJ sobre temas muito caros ao ambiente escolar como tolerância, respeito, justiça, liberdade, cooperação, cidadania dentre outros. Pautados 
DOI: $10.12957 / \mathrm{e}-\mathrm{mosaicos} .2019 .42284$

nos estímulos de um trabalho reflexivo e crítico sobre as diversas questões postas no mundo de hoje.

As diversas instâncias sociais têm impacto na infância. Entre atitudes desrespeitosas, agressivas, indiferentes, intolerantes e sem questionamento dos adultos, muitas vezes as crianças veem, presenciam em seu dia a dia. Ao conviver diariamente com esses comportamentos, vão naturalizando e reproduzindo, tais práticas. Essa reprodução é vista quando acontecem os conflitos no cotidiano, tendo dificuldades na mediação dos mesmos.

Nota-se também uma grande influência da mídia, tanto no comportamento quanto no pensamento. Nos meios de comunicação vemos diversas notícias veladas ditando regras e normas para viver; em ambientes punitivistas, crianças são estimuladas, muitas vezes, a serem submissas e conformistas, contribuindo para uma padronização e reprodução social de estereótipos e preconceitos que afetam direta e indiretamente as crianças.

Os projetos que trabalham a mediação de conflitos, através dos debates sobre o que acontece no cotidiano, se mostram vitais para problematizar a crescente onda de conservadorismo no Brasil e formar futuros adultos capazes de respeitar e dialogar em/com a sociedade. Deste modo, buscamos mostrar nosso compromisso com os estudantes ao levarmos em consideração suas colocações e percepções para orientarmos nosso trabalho sobre a mediação de conflitos escolares. Por meio de leituras específicas, buscamos promover reflexões para desestabilizar suas hipóteses pré-concebidas; estimulamos a argumentação pautadas no direito e respeito ao outro, sem desprezar a empatia; trabalhamos com rodas, pois são importantes na prática pedagógica pautada em um saber-fazer impregnado de diálogo e reflexão; por fim, temos a compreensão que os participantes da vida na escola têm suas vozes e angústias que precisam ser ouvidas.

Como resultados apresentam-se: (1) os estudantes estão mais independentes em relação à reflexividade dos próprios conflitos, buscando auxílio de um adulto somente quando necessário; (2) ainda se desentendem, mas buscam o diálogo diante a um conflito; (3) estão começando a compreender os limites e as possibilidades das próprias ações.

Diante do que foi apresentado até então, indicamos duas abordagens de análises: i) que o diálogo deve ser entendido como uma prática pedagógica sensível à realidade escolar; ii) que a construção de um debate que envolva autonomia, moral e ética perpassa por uma reflexão em que a criança deva ser encarada como sujeito ativo no processo de dialogicidade e reflexão sobre o mundo.

\section{REFERÊNCIAS}

ALVES, W. B.; MATTOS, C. L. G. Outros saberes sobre a escola: a voz do aluno na pesquisa em educação. In: Maria do Socorro Lucena Lima; Maria Marina Dias Cavalcante; José Albio Moreira de Sales; Isabel Maria Sabino de Farias. (Org.). 
DOI: $10.12957 / \mathrm{e}-$ mosaicos.2019.42284

Didática e prática de ensino na relação com a escola. 1ed.Fortaleza: EdUECE, 2015, v. 1 , p. $03435-03446$.

ARROYO, M. G. Quando a violência infanto-juvenil indaga a pedagogia. Educação e Sociedade, Campinas, v. 28, n. 100, p. 787-807, 2007.

ASSOCIAÇÃO BRASILEIRA DE PROTEÇÃO À INFÂNCIA E ADOLESCÊNCIA (ABRAPIA). Programa de redução do comportamento agressivo entre estudantes. 2002. Disponível em: <www.bullying.com.br>. Acesso em: 09 de abril de 2019.

BRASIL. Secretaria de Educação Fundamental. Parâmetros curriculares nacionais: introdução aos parâmetros curriculares nacionais / Secretaria de Educação Fundamental. - Brasília : MEC/SEF, 1997.

BRAUN, Patricia; MORAIS, Jaqueline de Fatima dos S.; OLIVEIRA, Cristiane Gomes; ALMEIDA, Mônica Andréa O. Rodas em sala de aula: estratégias de ensino e de aprendizagem nos anos iniciais do ensino fundamental. Cadernos da Pedagogia. São Carlos, Ano 3 v.3 n.6, p. 80-91, jul - dez. 2009.

DE LA TAILLE, Yves. Limites: Três dimensões educacionais. São Paulo: Ática, 2000.

DEVRIES, R.; ZAN, B. A ética na Educação Infantil: o ambiente sócio-moral na escola. Porto Alegre: Artes Médicas, 1998.

FANTE, C. Fenômeno Bullying: como prevenir a violência nas escolas e educar para a paz. São Paulo: Verus, 2005.

GUARESCHI, A. P.; SILVA, M. R. da. (Coord.) Bullying mais sério do que se imagina. 2a. ed. Porto Alegre: Mundo Jovem, EDIPUCRS, 2008.

KEMMIS, S.; MCTAGGART, R. Como planificar la investigación-acción. Barcelona: Editorial Alertes, 1988.

LOPES NETO, A. A. Bullying: Comportamento Agressivo entre Estudantes. Jornal de Pediatria, (Rio J.) no. 81, no.5 suppl. Porto Alegre Nov. 2005. $164-172$. 
DOI: $10.12957 /$ e-mosaicos.2019.42284

MATTOS, C. L. G. de; CASTRO, P. A. (2010) Entrevista como instrumento de pesquisa nos estudos sobre fracasso escolar. In: IV Seminário Internacional de Pesquisa e Estudos Qualitativos - Pesquisa Qualitativa: rigor em questão, Rio Claro. IV SEMINÁRIO INTERNACIONAL DE PESQUISA E ESTUDOS QUALITATIVOS. AcesSo: 25 mar. 2018. Disponível em: http://arquivo.sepq.org.br/IVSIPEQ/Anais/artigos/42.pdf

Recebido em 28 de abril de 2019

Aceito em 27 de agosto de 2019

A e-Mosaicos Revista Multidisciplinar de Ensino, Pesquisa, Extensão e Cultura do Instituto de Aplicação Fernando Rodrigues da Silveira (CAp-UERJ) está licenciada com uma Licença Creative Commons - Atribuição-NãoComercial 4.0 Internacional.

Os direitos autorais de todos os trabalhos publicados na revista pertencem ao(s) seu(s) autor(es) e coautor(es), com o direito de primeira publicação cedido à e-Mosaicos.

Os artigos publicados são de acesso público, de uso gratuito, com atribuição de autoria obrigatória, para aplicações de finalidade educacional e não-comercial, de acordo com o modelo de licenciamento Creative Commons adotado pela revista. 